\title{
Manual therapy as a conservative treatment for adolescent idiopathic scoliosis: a systematic review Michele Romano* and Stefano Negrini
}

\author{
Address: ISICO (Italian Scientific Spine Institute), Milan, Italy \\ Email: Michele Romano* - michele.romano@isico.it; Stefano Negrini - stefano.negrini@isico.it \\ * Corresponding author
}

Published: 22 January 2008

Scoliosis 2008, 3:2 doi:10.1186/1748-7/61-3-2

This article is available from: http://www.scoliosisjournal.com/content/3/I/2

(C) 2008 Romano and Negrini; licensee BioMed Central Ltd.

This is an Open Access article distributed under the terms of the Creative Commons Attribution License (http://creativecommons.org/licenses/by/2.0), which permits unrestricted use, distribution, and reproduction in any medium, provided the original work is properly cited.
Received: II December 2007

Accepted: 22 January 2008

\begin{abstract}
Background: The treatment of adolescent idiopathic scoliosis is contingent upon many variables. Simple observation is enough for less serious curvatures, but for very serious cases surgical intervention could be proposed. Between these there is a wide range of different treatments. Manual therapy is commonly used: the aim of this paper is to verify the data existing in the literature on the efficacy of this approach.

Methods: A systematic review of the scientific literature published internationally has been performed. We have included in the term manual therapy all the manipulative and generally passive techniques performed by an external operator. In a more specific meaning, osteopathic, chiropractic and massage techniques have been considered as manipulative therapeutic methods. We performed our systematic research in Medline, Embase, Cinhal, Cochrane Library, Pedro with the following terms: idiopathic scoliosis combined with chiropractic; manipulation; mobilization; manual therapy; massage; osteopathy; and therapeutic manipulation. The criteria for inclusion were as follows: Any kind of research; diagnosis of adolescent idiopathic scoliosis; patients treated exclusively by one of the procedures established as a standard for this review (chiropractic manipulation, osteopathic techniques, massage); and outcome in Cobb degrees.
\end{abstract}

Results: We founded 145 texts, but only three papers were relevant to our study. However, no one of the three satisfied all the required inclusion criteria because they were characterized by a combination of manual techniques and other therapeutic approaches.

Conclusion: The lack of any kind of serious scientific data does not allow us to draw any conclusion on the efficacy of manual therapy as an efficacious technique for the treatment of Adolescent idiopathic scoliosis.

\section{Background}

Idiopathic scoliosis is a pathology that affects approximately $2 \%$ of adolescents $[1,2]$. Various treatment procedures are proposed, according to severity of curvature, hump height, age at diagnosis, spinal stiffness and skeletal maturity. One of the major problems in the treatment of this pathology is the lack of a reliable prognostic tool for its possible evolution. There are scolioses that, once discovered, don't worsen anymore, whereas others are characterized by a rapid and dramatic worsening - especially during the pubertal growth spurt - or that continue to worsen in adulthood. This particular variety of behaviours 
allows us to employ two alternative methods of therapeutic approach:

1. The patients are not subjected to screening or to previous treatments. This forces the persons who are affected by serious scoliosis to begin treatment later, causing negative repercussions on the final results or the need to perform an important surgical intervention.

2. The patients are subjected to a screening (school, family, pediatrician); all risky scolioses are identified (namely those that exceed a certain degree according to age) and are referred to a program of conservative treatment, according to the potential risk of evolution. Furthermore, this procedure has a disadvantage in that it involves a long and expensive treatment even for the subject who is not affected by an progressive scoliosis.

The steps of non-surgical intervention can start with a simple observation, if no particularly important curvature is discovered and the subject is not at a particularly risky age. Alternatively, it is possible to adopt different therapeutic solutions, such as the use of braces [3-13], which are intended to correct spinal development when curvature evolution is not controlled through other techniques. Many studies have been conducted regarding the efficacy of such a therapeutic approach, whose validity is nevertheless confirmed by official medicine [5,8,14-16]. Another common therapeutic approach is the use of physical exercises [17-27] whose efficacy is not universally recognized, even if two systematic review [28] has been published during recent years. The results of these works do not allow us to state with reasonable certainty that this procedure will represent an efficacious treatment for idiopathic scoliosis, given that the studies on which the aforementioned review were based had been performed using different techniques. However, the possibility of comparing the best results from the various treated groups with the respective control groups encourages us to carry out new research with a better scientific design $[28,29]$. Besides the above-described treatments, it is possible to mention a range of alternative therapeutic proposals, such as the implantation of a dental bite or of podalic insoles. Their efficacy, however, has not been supported by published studies. A therapeutic approach that seems more and more common for the conservative treatment of adolescent idiopathic scoliosis includes manual techniques proposed by chiropractors and osteopaths. These techniques are favoured by their progressive popularity within the wider and wider panorama of alternative therapies [30-38].

The purpose of this study is to present a systematic review of the international scientific literature in order to verify the therapeutic efficacy of these procedures, which include all the manipulative and generally passive techniques performed by an external operator to treat idiopathic scoliosis. In a more specific meaning, osteopathic, chiropractic and massage techniques have been considered manipulative therapeutic methods.

\section{Methods}

We conducted systematic research in the following databases: Medline, Embase, Cinhal, Cochrane Library and Pedro. The research was carried out in May of 2005 without time, meaning without fixing a starting date or imposing language restrictions. The key phrases were as follows: Idiopathic scoliosis (combined with chiropractic); manipulation; mobilization; manual therapy; massage; osteopathy; and therapeutic manipulation. The research was completed through the analysis of the other papers published and available, thanks to the following specialized databases: Index to Chiropractic Literature, Osteomed, Osteopathic Research Web, and N.C.C.A.M.

The criteria for inclusion were as follows:

- Subjects: Diagnosis of Adolescent idiopathic scoliosis;

- Type of treatment received: Exclusively one of the procedures fixed as a standard for this review (chiropractic manipulation, osteopathic techniques, massage);

- Outcome: Cobb degrees;

- Type of study: Any kind of research.

The decision not to apply highly restrictive selection criteria but to include studies conducted with different procedures was determined through the presumption that homogeneous trials are seldom performed.

\section{Results}

\section{Main results}

A total of seventy-three papers were found in this research in PubMed/Medline (Table 1). In the other databases

Table I: Results of the research in PubMed according to the keywords used.

\begin{tabular}{lc}
\hline Combination of keywords & Papers found \\
\hline Idiopathic scoliosis AND chiropractic & 13 \\
Idiopathic scoliosis AND manipulation & 20 \\
Idiopathic scoliosis AND massage & 18 \\
Idiopathic scoliosis AND mobilization & 28 \\
Idiopathic scoliosis AND manual therapy & 3 \\
Idiopathic scoliosis AND therapeutic manipulation & 2 \\
\hline Total of papers retrieved (excluding & 73 \\
duplicates) & \\
\hline
\end{tabular}


(Pedro, Cinhal, Cochrane Library, Embase), excluding papers already found in PubMed, we retrieved:

- No reviews in Cochrane Library;

- Four papers in Pedro;

- Twenty papers in Embase;

- Fifty-three papers in Index to Chiropractic Literature;

- No papers in Osteomed and Osteopathic Research Web. In these two databases it was possible to find papers concerning adult scoliosis. In any case there were no research trials but only case reports or more general subjects.

- No papers in N.C.C.A.M. (National Centre for Complementary and Alternative Medicine).

After excluding duplicates, among the 145 texts we found, only three papers were relevant to our study. No one, however, satisfied all the required inclusion criteria. Nevertheless, we present these papers for possible future research.

\section{Possibly relevant papers not satisfying the inclusion criteria}

Out of the three possibly relevant papers, two were non controlled studies (Table 2).

The first paper [31] is a non-controlled cohort study examining the combined effect of spinal manipulation and other procedures, such as traction and exercises, whose results don't give clear information about the efficacy of the specific manual therapy. The nineteen examined subjects (ranging in age from fifteen to sixty-five years) underwent three weekly treatment sessions for four to six weeks. The average Cobb angle at the beginning of treatment was $28^{\circ}$, and at the end it was $11^{\circ}$ with an average improvement of $17^{\circ}$. The best improvement observed was $38^{\circ}$, and the smallest was $8^{\circ}$.

The second study [32] concerned a treatment combining chiropractic manipulation with podalic insoles, the latter being prescribed when curvature convexity concerned the shorter leg. All subjects received postural advice. The selected subjects numbered forty-two (twenty-six females, sixteen males) ranging in age from six to seventeen years, with curvatures between Cobb $4^{\circ}$ and $22^{\circ}$. Treatment was executed for an average of fourteen months, intended as periods between the first session and the first follow-up, with an average of three sessions per month. The results showed an average improvement of $0.9^{\circ}$. Specifically, an improvement was observed in ten cases (19\%), a worsening in six cases $(11 \%)$ and no changes in thirty-seven cases $(70 \%)$. Two cases showed an inversion of scoliosis on the frontal plane, with a transfer of the curvature to the opposite direction. These cases were considered as having improvement. On the basis of results, whose analysis was conducted by a single examiner, the authors stated that chiropractic manipulation, associated with the use of insoles and postural advice, did not produce an improvement in scoliotic curvature.

The third paper is a pilot study to explore patient recruitment and compliance, treatment standardization and outcome measure selection. Author's conclusion showed the viability for a larger randomized trial [39].

\section{Case reports}

Moreover, we found three case reports $[33,34,40]$ concerning the treatment of young subjects with idiopathic scoliosis: The former [34] showed the effect of a manipulative cycle during a period of seventeen months in association with an exercise program, and involved two adolescents having two extremely different types of scoliosis $\left(16^{\circ}\right.$ and $\left.60^{\circ}\right)$. Among the many weak points of this study (only two subjects with very different scolioses and the use of combined treatment techniques), we can also mention that, as outcome instruments, the operators did not use objective methods as Cobb degrees but instead used visual evaluation and palpation, including shoulder asymmetry, axillae asymmetry and position of scapula angle. The authors observed that scoliosis decompensation was successfully stopped and that the effects of correction remained for 10 years.

The second case report [33] studies the effect of a manipulative cycle during a period of three months in association with a treatment involving night-time electric stimulations over a period of nine months on a patient with juvenile idiopathic scoliosis. The curvature progressed at a rate of 1.0 degree per month over the previous nine months. The patient's curvature was successfully stopped at 27 degrees and subsequently reversed to 17 degrees in the first three months of therapy.

Table 2: Methodological characteristics and results of the two non controlled studies retrieved.

\begin{tabular}{cccccc}
\hline Paper & Study design & No. subjects & Avg. age & Initial ${ }^{\circ}$ Cobb $^{\text {Final }}{ }^{\circ}$ Cobb \\
\hline Morningstar [31] & Non-controlled & 19 & $15-65$ & 28 average & average 11 \\
Lantz [32] & Non-controlled & 42 & $6-17$ & Improvement $0.9^{\circ}$
\end{tabular}


Tha last paper [40] is a case series of 3 atypical patient: a left thoracic, idiopathic scoliosis after Harrington rod instrumentation, a left thoracic scoliosis secondary to Scheuermann's Kyphosis and a primary idiopathic thoracic levoscoliosis. Patients were treated with an active rehabilitation program including spinal manipulation and an external head and body weighting system. After 12 weeks of treatment authors found an apparent reduction in Cobb degrees in all 3 cases, but they admit the possibility of a placebo effect because of the lack of a control group.

\section{Discussion}

None of the papers retrieved had the characteristics required for inclusion in our review. Indeed, we found only two research trials. Neither of the two had a control group, but each was characterized by a combination of manipulative procedures and other therapeutic approaches. The results of these two research studies are discordant. In the paper written by Morningstar et al [31]the result seems extremely positive (an average improvement of $17^{\circ} \mathrm{Cobb}$ after four to six weeks of treatment), while the conclusions of the study conducted by Lantz et al. [32] show an absolute ineffectiveness of the applied treatment. It must be stated that the first study had certain flaws: The recruited group of subjects presented an excessively wide age range, but no control group was designed and no follow-up observation was performed after treatment. Some doubts also arise as to the results, which seem so extraordinary to suggest a deep reflection to all health workers engaged in the conservative treatment of scoliosis throughout the world.

Case reports are not a valuable aid. Even when summing up single results, in the absence of homogeneous studies the data is absolutely inadequate (only two cases related to young patients, always characterized by the association of manual treatment with other techniques). None of the other papers allowed us to obtain supplementary information that could be deemed useful.

Generally, for manual therapy we can underline that even if we were to extend our inclusion criteria, the available papers are completely inadequate for a review. We can compare these results with those obtained using different conservative techniques, such as physical therapy or braces. Regarding physical exercises, few trials have been conducted as to their efficacy. We can mention just two systematic reviews $[28,41]$. The quality of the retrieved papers is not very high, given the lack of randomized controlled studies. However, the results are very interesting for future research and suggest the possible usefulness of exercises. The most recent review [41] published in 2005, asserts that at this state of the art, physical therapy and the application of a brace have the same reliability value. Of course, in the scientific literature we can find a greater number of papers on treatment using a brace. However, for this technique we still lack the certainty that the brace is an absolutely reliable therapeutic technique.

In conclusion, the data reported above does not allow us to evaluate the efficacy of manual therapy techniques in adolescent idiopathic scoliosis. These results confirm the urgent needof scientific studies with at least one control group, to be performes by operators using such techniques, to demonstrate their validity.

\section{Authors' contributions}

Both authors participated in all phases of the study, excluding data collection, that was performed by MR alone.

\section{References}

I. Asher MA, Burton DC: Adolescent idiopathic scoliosis: natural history and long term treatment effects. Scoliosis 2006, I:2.

2. Weinstein SL: Idiopathic scoliosis. Natural history. Spine 1986, I I:780-783.

3. Negrini S: Corsetti e riabilitazione per il paziente affetto da scoliosi idiopatica adolescenziale. GIMR - Giornale Italiano di Medicina Riabilitativa 2003, I 7:73-79.

4. Negrini S, Marchini G, Tomaello L: Efficacy of the Symmetric, Patient-oriented, Rigid, Three-Dimensional (SPoRT) concept of bracing for scoliosis: a pair-controlled retrospettive short-term study on the Sforzesco Brace. Edited by: SOSORT ICCMDSM. Poznan, Poland, ; 2006.

5. Weiss HR: Adolescent idiopathic scoliosis: the effect of brace treatment on the incidence of surgery. Spine 200I, 26:2058-2059.

6. Weiss HR, Weiss GM: Brace treatment during pubertal growth spurt in girls with idiopathic scoliosis (IS): a prospective trial comparing two different concepts. Pediatr Rehabil 2005, 8:199-206.

7. Rigo M, Negrini S, Weiss HR, Kotwicki T, Grivas T, Maruyama T, Members of the Study group On Scoliosis Orthopaedic and Rehabilitation Treatment (SOSORT): Brace action: where to push and why. SOSORT 2005 Consensus Paper - Topic 2. [http:// www.isico.it].

8. Nachemson AL, Peterson LE: Effectiveness of treatment with a brace in girls who have adolescent idiopathic scoliosis. A prospective, controlled study based on data from the Brace Study of the Scoliosis Research Society. J Bone Joint Surg Am 1995, 77:815-822.

9. Rowe DE, Bernstein SM, Riddick MF, Adler F, Emans JB, GardnerBonneau D: A meta-analysis of the efficacy of non-operative treatments for idiopathic scoliosis. J Bone Joint Surg Am 1997, 79:664-674.

10. von Deimling U, Wagner UA, Schmitt O: [Long-term effect of brace treatment on spinal decompensation in idiopathic scoliosis. A comparison of Milwaukee brace--Cheneau corset]. Z Orthop Ihre Grenzgeb 1995, 133:270-273.

II. Katz DE, Richards BS, Browne RH, Herring JA: A comparison between the Boston brace and the Charleston bending brace in adolescent idiopathic scoliosis. Spine 1997, 22:1302-1312.

12. Upadhyay SS, Nelson IW, Ho EK, Hsu LC, Leong JC: New prognostic factors to predict the final outcome of brace treatment in adolescent idiopathic scoliosis. Spine 1995, 20:537-545.

13. Lonstein JE, Winter RB: The Milwaukee brace for the treatment of adolescent idiopathic scoliosis. A review of one thousand and twenty patients. J Bone Joint Surg Am 1994, 76:1207-1221.

14. Howard A, Wright JG, Hedden D: A comparative study of TLSO, Charleston, and Milwaukee braces for idiopathic scoliosis. Spine 1998, 23:2404-24II.

15. Price CT, Scott DS, Reed FR Jr., Sproul JT, Riddick MF: Nighttime bracing for adolescent idiopathic scoliosis with the Charles- 
ton Bending Brace: long-term follow-up. J Pediatr Orthop 1997, 17:703-707.

16. Upadhyay SS, Burwell RG, Webb JK: Hump changes on forward flexion of the lumbar spine in patients with idiopathic scoliosis. A study using ISIS and the Scoliometer in two standard positions. Spine 1988, 13:|46-15I.

17. Stagnara P: . Expansion Scientifique Francaise 1990.

18. Negrini A, Verzini N, Parzini S, Negrini A, Negrini S: Role of physical exercise in the treatment of mild idiopathic adolescent scoliosis. Eur Med Phys 2001:181-190.

19. Stone B, Beekman C, Hall V, Guess V, Brooks HL: The effect of an exercise program on change in curve in adolescents with minimal idiopathic scoliosis. A preliminary study. Phys Ther 1979, 59:759-763.

20. Negrini A, Sibilla P, Negrini S: La cinesiterapia nel trattamento della scoliosi: nuovi orientamenti metodologici. Riabilitazione oggi 1992, 9: II-15.

21. Negrini S, Negrini A, Sibilla P: Reeducation of the scoliotic patient: ; Barcelona (ESP) Lyon (F). ; 1996:68-7I.

22. Farady JA: Current principles in the nonoperative management of structural adolescent idiopathic scoliosis. Phys Ther 1983, 63:512-523.

23. Mollon G, Rodot JC: Scolioses structurales mineures et kinesithérapie. Kinesithérapie scientifique 1986:47-56.

24. Mollon G: Kinesitérapie des scolioses. Encycl Med Chir 26300A IO 4607.

25. Weiss HR: Influence of an in-patient exercise program on scoliotic curve. Ital J Orthop Traumatol 1992, 18:395-406.

26. Negrini S, Aulisa L, Ferraro C, Fraschini P, Masiero S, Simonazzi P, Tedeschi $C$, Venturin A: Italian guidelines on rehabilitation treatment of adolescents with scoliosis or other spinal deformities. Eura Medicophys 2005, 4I:183-20I.

27. Perdriolle R: La scoliose. Son ètude tridimensionelle. Maloine Edieur, Paris 1979.

28. Negrini S, Antonini G, Carabalona R, Minozzi S: Physical exercises as a treatment for adolescent idiopathic scoliosis. A systematic review. Pediatr Rehabil 2003, 6:227-235.

29. Weiss HR, Negrini S, Rigo M, Kotwicki T, Grivas T, Maruyama T, Members of the Study group On Scoliosis Orthopaedic and Rehabilitation Treatment (SOSORT): Physical Exercises in the Treatment of Idiopathic Scoliosis. SOSORT 2005 Consensus Paper - Topic I. [http://www.isico.it].

30. Possin DM, Mawhiney RB: The efficacy of chiropractic treatment in adult lumbar scoliosis. Chiropractic 1989, 2:99-102.

31. Morningstar MW, Woggon D, Lawrence G: Scoliosis treatment using a combination of manipulative and rehabilitative therapy: a retrospective case series. BMC Musculoskelet Disord 2004, 5:32.

32. Lantz CA, Chen J: Effect of chiropractic intervention on small scoliotic curves in younger subjects: a time-series cohort design. I Manipulative Physiol Ther 200I, 24:385-393.

33. Aspegren DD, Cox JM: Correction of progressive idiopathic scoliosis utilizing neuromuscular stimulation and manipulation: a case report. J Manipulative Physiol Ther 1987, 10:147-156.

34. Niesluchowski W, Dabrowska A, Kedzior K, Zagrajek T: The potential role of brain asymmetry in the development of adolescent idiopathic scoliosis: a hypothesis. J Manipulative Physiol Ther 1999, 22:540-544.

35. Eriksen K: Correction of juvenile idiopathic scoliosis after primary upper cervical chiropractic care: a case study. Chiro Res J 1996, 3:25-33.

36. Bosler J: Scoliosis cured by manipulation of the neck. Med J Aust 1979: I-95.

37. Mawhiney RB: Chiropractic proof in scoliosis care. Digest Chiro Econ 1984:65-70.

38. Arthur BE, Nykoliation JW, Cassidy J: Adult idiopathic scoliosis-a review and case study. Eur / Chiro 1986, 34:46-53.

39. Rowe DE, Feise RJ, Crowther ER, Grod JP, Menke JM, Goldsmith CH, Stoline MR, Souza TA, Kambach B: Chiropractic manipulation in adolescent idiopathic scoliosis: a pilot study. Chiropr Osteopat 2006, 14:15.

40. Morningstar MW, Joy T: Scoliosis treatment using spinal manipulation and the Pettibon Weighting System: a summary of 3 atypical presentations. Chiropr Osteopat 2006, I 4:I.

4I. Lenssinck ML, Frijlink AC, Berger MY, Bierman-Zeinstra SM, Verkerk $K$, Verhagen AP: Effect of bracing and other conservative inter- ventions in the treatment of idiopathic scoliosis in adolescents: a systematic review of clinical trials. Phys Ther 2005, 85: 1329-1339.
Publish with Biomed Central and every scientist can read your work free of charge

"BioMed Central will be the most significant development for disseminating the results of biomedical research in our lifetime. "

Sir Paul Nurse, Cancer Research UK

Your research papers will be:

- available free of charge to the entire biomedical community

- peer reviewed and published immediately upon acceptance

- cited in PubMed and archived on PubMed Central

- yours - you keep the copyright

Submit your manuscript here:

http://www.biomedcentral.com/info/publishing_adv.asp 